\title{
PENGARUH AKUN YOUTUBE “LITTLE FOX CHINESE"DALAM MEMPERKUAT LITERASI DIGITAL SISWA
}

\author{
Wafda Nabila Haqqie, Primardiana Hermilia Wijayati. \\ Universitas Negeri Malang \\ Program Studi Bahasa Mandarin S1 \\ E-mail: primardiana.hermilia.fs@um.ac.id
}

\begin{abstract}
Abstrak
Artikel ini merupakan hasil penelitian tentang pemanfaatan teknologi internet dan platform digital. Pembelajaran digital sesuai dengan prinsip era revolusi industri 4.0, yaitu dapat membentuk generasi kreatif, inovatif, serta kompetitif. Era Revolusi Industri 4.0 juga menitikberatkan pola pada digitalisasi, termasuk dalam literasi digital.

Tujuan dari penelitian ini adalah mendeskripsikan penguatan literasi digital siswa kelas $\mathrm{X}$ melalui pemanfaatan akun YouTube "Little Fox Chinese" pada matapelajaran bahasa Mandarin di SMAK Santa Maria Malang. Penelitian ini menggunakan metode kuantitatif, dengan instrumen penelitian kuisioner dan angket.

Hasil penelitian menunjukkan bahwa memanfaatkan akun YouTube "Little Fox Chinese" dapat memperkuat literasi digital mereka terutama learning skills. Siswa menggunakan akun YouTube "Little Fox Chinese" mengalami kesulitan dalam menjabarkan dan menyampaikan isi dari video akun YouTube "Little Fox Chinese" atau terkait dengan critical thinking skills disebabkan oleh kurangnya kemampuan menganalisis isi video, namun keterampilan learning skills lainnya sangat baik dan memanfaatkan akun YouTube "Little Fox Chinese" menuai respon positif dari siswa kelas X setelah dalam mempelajari bahasa Mandarin.
\end{abstract}

Kata kunci: Literasi Digita, Learning Skill, YouTube "Little Fox Chinese", bahasa Mandarin

\section{A. PENDAHULUAN}

Saat ini banyak sekolah yang menyelenggarakan gerakan literasi digital, terutama pada jenjang SMA. Literasi digital diperlukan karena Revolusi Industri 4.0 telah membawa perubahan dalam berbagai aspek kehidupan manusia, salah satunya adalah dunia pendidikan (Schwab, 2016) dan era Revolusi Industri 4.0 juga menitikberatkan pola pada digitalisasi. Oleh karena itu, penguatan literasi digital sangat diandalkan. Penguatan literasi digital bisa dilakukan jika memanfaatkan peran media digital. Adanya media digital diharapkan bisa membantu siswa untuk memperkuat literasi digital mereka pada mata pelajaran bahasa Mandarin. Terdapat empat penyebab orang memilih media yaitu Demonstration, Familiarity, Clarity, Active Learning (Sadirman A, 1996:84). Media digital merupakan media yang familiar bagi siswa, karena dalam kehidupan sehari-harinya hampir tidak lepas dari teknologi dan media digital.

Memanfaatkan peran teknologi intenet, seperti media sosial dan platform digital secara optimal dengan peran teknologi tersebut sebagai sumber informasi mengenai pengetahuan dan guruan merupakan salah satu inovasi dalam penguatan literasi digital. Hal tersebut sesuai dengan era revolusi industri 4.0, yaitu dapat membentuk generasi kreatif, inovatif, serta kompetitif.

Berdasarkan hasil penelusuran, terdapat beberapa penelitian yang relevan dengan penelitian ini, diantaranya yaitu penelitian dari Setyaningsih dkk. tahun 2019 dengan judul 
"Model Penguatan Literasi Digital Melalui Pemanfaatan E-Learning". Pada penelitian Setyaningsih dkk. membahas tentang pemanfaatan media digital untuk meningkatkan kemampuan literasi digital di Universitas Darussalam Gontor dan menemukan sebuah model penguatan literasi digital yang dilakukan di perguruan tinggi berbasis pesantren tersebut. Peningkatan kemampuan literasi digital yang digunakan pada penelitian milik Setyaningsih dkk. adalah melalui pemanfaatan e-learning. Selanjutnya, model penguatan literasi digital yang digunakan adalah elemen communication and collaboration. Elemen communication and collaboration dalam literasi digital, terdapat komponen individual competence yang terdiri dari use skill, critical understanding, dan communicative abilities (Setyaningsih, 2010). Dengan memperkuat tiga komponen tersebut dalam e-learning membuat kemampuan literasi digital komunikator semakin kuat. Pada penelitian Setyaningsih dkk. tahun 2019 dapat menjadi salah satu rujukan peneliti terkait pemetaan konten edukasi di media sosial sebagai upaya memperkuat literasi digital mereka.

Media sosial yang sedang diminati oleh siswa saat ini adalah YouTube. YouTube telah menjadi salah satu media sosial paling populer di dunia, lebih dari satu miliar pengguna dengan lebih dari 6 miliar jam waktu menonton setiap bulan (Kwok dalam Lam, 2019), dan hasil penelitian Lam (2019) juga menunjukkan bahwa video YouTube tampil lebih baik dalam menargetkan pemirsa yang berusia 45 tahun pada tahun ketiga dan memiliki peningkatan signifikan dalam persentase pemirsa yang berada dalam usia yang ditargetkan pada 45 tahun atau lebih tua $(62,0 \%$ vs $46,0 \%$, df $=2$, chi $=147,46, \mathrm{p}<0,01)$, sehingga dapat dikatakan bahwa YouTube saat ini menjadi salah satu tujuan utama masyarakat terutama kalangan siswa untuk mencari beragam konten dalam bentuk video salah satunya konten edukasi.

YouTube Creator Academy (2018) berpendapat bahwa salah satu tujuan utama YouTube adalah konten video yang bersifat edukasi merupakan salah satu fokus utama yang perlu untuk dikembangkan secara serius, mengingat setiap hari lebih dari 1 miliar video terkait proses pembelajaran ditonton di YouTube. Beberapa contoh akun YouTube berkonten pedidikan yang berhubungan dalam pembelajaran bahasa Mandarin: Tjen Wandra, Nihao Indonesia dan Little Fox Chinese. Tjen Wandra merupakan akun YouTube pembelajaran bahasa Mandarin yang dikelola oleh YouTuber Indonesia yaitu Tjen Wandra. Beliau pernah menempuh studi S1 di Beijing, oleh karena itu beliau membagikan video pengalaman dan pembelajaran bahasa Mandarin, China. Misi akun YouTube ini agar memudahkan masyarakat Indonesia belajar bahasa Mandarin. kedua akun YouTube Nihao Indonesia adalah sebuah platform digital Indonesia yang terpecaya di Taiwan. Tujuan dari akun YouTube tersebut untuk memberikan informasi, tips, traveling, food dan semua informasi seru orang Indonesia di Taiwan. Terakhir, Little Fox Chinese adalah akun YouTube program bahasa yang memungkinkan siapa saja untuk belajar bahasa Mandarin dengan cara yang menyenangkan dan menarik. Ketika siswa menonton video YouTube Little Fox Chinese, mereka dengan cepat membangun kosa kata dan kelancaran dengan cara yang alami dan otentik. Akun tersebut juga setiap minggu mengunggah dua video baru ke saluran YouTube mereka.

Adapun YouTube merupakan salah satu media yang berkembang saat ini dan diminati oleh khalayak terutama generasi millenial, karena dengan adanya media YouTube setiap orang dapat mengunggah video secara gratis dan dengan durasi yang tidak ada batasnya. Media digital YouTube juga membuat siswa bisa bertukar informasi dan mendapatkan banyak informasi yang ada di dalamnya termasuk informasi pendidikan. Dengan beragam basis argumen yang dikemukakan di atas, artikel ini berfokus pada penguatan elemen learning skills literasi digital dengan memanfaatkan akun YouTube Little Fox Chinese.

\section{B. METODE PENELITIAN}


Penelitian ini menggunakan metode kuantitatif deskriptif untuk mengetahui bahwa akun YouTube "Little Fox Chinese" dapat memperkuat literasi digital siswa. Instrumen yang digunakan peneliti adalah angket. Angket adalah seperangkat pertanyaan atau pernyataan tertulis yang ditunjukan kepada responden untuk dijawab (Sugiyono, 2011:142). Responden menerima angket yang berperan sebagai informasi pendukung dalam mengetahui penguatan literasi digital siswa kelas X MIA 2 pada matapelajaran bahasa Mandarin melalui pemanfaatan akun YouTube "Little Fox Chinese" di SMAK Santa Maria Malang.

Kegiatan pengumpulan data dilakukan pada tanggal 18 Mei 2020. Pengumpulan data dilakukan secara daring melalui laman google form yang dibagikan kepada seluruh responden. Kegiatan pengumpulan data pada tanggal $18 \mathrm{Mei}$, peneliti memperkenalkan terlebih dahulu akun YouTube "Little Fox Chinese" kepada responden dalam memperkuat literasi digital mereka terutama dalam matapelajaran bahasa Mandarin, terakhir responden mengisi lembar angket yang telah disebarkan. Setelah data dari dua instrumen terkumpul, kemudian data tersebut dianalisis dengan metode kuantitatif deskriptif.

\section{HASIL DAN PEMBAHASAN}

Penelitian ini menemukan penguatan literasi digital siswa di SMAK Santa Maria Malang. Fokus penelitian ini adalah penguatan literasi digital elemen learning skills, untuk mengetahui kemampuan literasi digital tersebut, peneliti menambahkan variable pada instrumen learning and innovation skills. Ada empat bagian learning and innovation skills. Setiap bagian mewakili kompetensi 4C yakni, critical thinking skills, creative thinking skills, communication skills, dan collaboration skills. Masing-masing bagian memiliki dua pernyataan yang diukur. Berikut peneliti menjabarkan hasil persentase:

Tabel 1. Learning Skills

\begin{tabular}{|c|c|c|c|c|c|c|}
\hline \multirow{2}{*}{ No. } & \multirow{2}{*}{ Learning Skills } & \multirow{2}{*}{ Pernyataan } & 1 & 2 & 3 & 4 \\
\hline & & & $\%$ & $\%$ & $\%$ & $\%$ \\
\hline \multirow[t]{2}{*}{1.} & \multirow{2}{*}{$\begin{array}{c}\text { Critical } \\
\text { Thinking Skills }\end{array}$} & $\begin{array}{l}\text { Menjabarkan isi dari video akun } \\
\text { YouTube "Little Fox Chinese". }\end{array}$ & 20 & 72 & 4 & 4 \\
\hline & & $\begin{array}{l}\text { Mampu menyampaikan isi dari video } \\
\text { akun YouTube "Little Fox Chinese". }\end{array}$ & 24 & 72 & 4 & 0 \\
\hline \multirow[t]{2}{*}{2.} & \multirow[t]{2}{*}{$\begin{array}{c}\text { Creative } \\
\text { Thinking Skills }\end{array}$} & $\begin{array}{l}\text { Kemampuan mendengarkan beragam } \\
\text { pendapat dari video akun YouTube } \\
\text { "Little Fox Chinese". }\end{array}$ & 28 & 64 & 8 & 0 \\
\hline & & $\begin{array}{l}\text { Menyuguhkan sebuah hal baru dari } \\
\text { akun YouTube "Little Fox Chinese". }\end{array}$ & 28 & 52 & 16 & 4 \\
\hline \multirow[t]{2}{*}{3.} & \multirow{2}{*}{$\begin{array}{l}\text { Communication } \\
\text { Skills }\end{array}$} & $\begin{array}{l}\text { Akun YouTube "Little Fox Chinese" } \\
\text { dapat membuat berkomunikasi dalam } \\
\text { bahasa Mandarin secara efektif dengan } \\
\text { orang lain. }\end{array}$ & 28 & 60 & 12 & 0 \\
\hline & & $\begin{array}{l}\text { Menginformasikan berbagai materi } \\
\text { pembelajaran bahasa Mandarin } \\
\text { menggunakan akun YouTube "Little } \\
\text { Fox Chinese. }\end{array}$ & 32 & 48 & 20 & 0 \\
\hline \multirow[t]{3}{*}{4.} & \multirow{3}{*}{$\begin{array}{l}\text { Collaboration } \\
\text { Skills }\end{array}$} & Memanfaatkan akun YouTube "Little & & & & \\
\hline & & $\begin{array}{l}\text { Fox Chinese" dalam berpartisipasi dan } \\
\text { berkontribusi pada kerja kelompok } \\
\text { secara merata. }\end{array}$ & 36 & 52 & 12 & 0 \\
\hline & & $\begin{array}{l}\text { Memanfaatkan akun YouTube "Little } \\
\text { Fox Chinese" dalam berkompromi } \\
\text { dengan anggota kelompok untuk }\end{array}$ & 36 & 56 & 8 & 0 \\
\hline
\end{tabular}


mencapai tujuan bersama.

Data yang disajikan dari tabel 1 menunjukan hasil persentase keterampilan learning skills setelah menggunakan akun Youtube "Little Fox Chinese" pada mata pelajaran bahasa Mandarin. Tabel tersebut menunjukkan siswa saat berliterasi digital telah mengusai elemen literasi digital yaitu learning skills yaitu keterampilan berpikir kreatif (creative thinking skill), keterampilan komunikasi (communication skill), dan keterampilan kolaborasi (collaboration skill,) kecuali, critical thinking skills. Terkait critical thinking skills, siswa mengaku mengalami kesulitan dalam menjabarkan dan menyampaikan isi dari video akun YouTube "Little Fox Chinese" disebabkan oleh kurangnya kemampuan menganalisis isi video, padahal kemampuan menganalisis sebuah permasalahan termasuk dalam aspek critical thinking skills yang harus dikuasai siswa. Seperti yang dikemukakan oleh Facione (2011) yaitu aspek critical thinking skills meliputi interpretasi, analis, eksplanasi, inferensi, evaluasi dan pengaturan diri. Penyebab kurangnya kemampuan siswa dalam menganalisis isi video karena siswa kurang memahami arti dari kosakata bahasa Mandarin yang ditampilkan di video, hal tersebut membuat siswa sulit menjabarkan dan menyampaikan isi dari video akun YouTube "Little Fox Chinese". Solusi dari permasalahan tersebut adalah dengan melibatkan siswa secara aktif di dalam kelas seperti tanya jawab atau mengerjakan tugas, agar merangsang siswa dalam berpikir kritis (Facione, 2011).

Siswa juga menemukan hal baru dalam memanfaatan akun YouTube "Little Fox Chinese" karena di akun YouTube tersebut dengan adanya beberapa playlist, yaitu: playlist folktales, culture, songs, dan early learning dalam bahasa Mandarin. Di dalam akun YouTube tersebut terdapat video animasi yang disertai hanzi (aksara china) dan pinyin, sehingga dapat menjadi media belajar bahasa Mandarin siswa. Hal tersebut sesuai dengan pernyataan Balcikanli (dalam Kabooha, 2015) yakni YouTube bisa digunakan sebagai kesempatan belajar bahasa kedua bagi siswa, mereka bisa menonton serta mendengarkan berbagai jenis bahan atau konten yang diucapkan.

YouTube bukan hanya bisa menjadi kesempatan belajar bahasa kedua bagi siswa, tetapi aplikasi YouTube seperti akun YouTube "Little Fox Chinese" juga bisa sebagai media refrensi tugas akhir mereka. Hasil data menunjukkan, seluruh responden sebanyak 25 siswa menggunakan media digital YouTube dalam project akhir bahasa Mandarin. Responden juga mengakui adanya media digital YouTube juga dapat menjadi referensi project akhir bahasa Mandarin mereka. Hal tersebut seperti disampaikan oleh YouTube Creator Academy (2018) bahwa salah satu tujuan utama YouTube adalah konten video yang bersifat edukasi merupakan salah satu fokus utama yang perlu untuk dikembangkan secara serius, mengingat setiap hari lebih dari 1 miliar video terkait proses pembelajaran ditonton di YouTube.

Sebagian besar siswa dapat memproduksi video YouTube sendiri dengan menggunakan akun YouTube "Little Fox Chinese" sebagai refrensi video secara gratis dan YouTube dengan konten pembelajaran bahasa Mandarin dalam bentuk media digital audio-visual sedang menjamur dikalangan siswa kelas X. Hal tersebut sesuai dengan pernyataan Nielsen (dalam Rahmawan, 2018) bahwa popularitas YouTube terkait dengan konten di media digital dalam bentuk video sedang menjamur dikalangan anak muda. Konten video YouTube sangat beragam salah satunya konten pendidikan/edukasi.

Berdasarkan beberapa pembahasan dapat disimpulkan bahwa akun YouTube "Little Fox Chinese" dapat memperkuat literasi digital dengan telah mengusai elemen literasi digital yaitu learning skills, meskipun siswa saat menggunakan akun YouTube "Little Fox Chinese" juga mengalami kesulitan dalam menjabarkan dan menyampaikan isi dari video akun YouTube "Little Fox Chinese" atau terkait dengan critical thinking skills disebabkan oleh kurangnya kemampuan menganalisis isi video. Akun YouTube "Little Fox Chinese" dalam 
pembelajaran bahasa Mandarin juga dapat sebagai refrensi project akhir video bahasa Mandarin siswa, karena popularitas akun YouTube "Little Fox Chinese" sedang menjamur dikalangan siswa Kelas X SMAK Santa Maria dan mampu menjadi alternatif penguatan literasi digital mereka terutama dalam matapelajaran bahasa Mandarin.

\section{KESIMPULAN}

Penelitian ini menemukan bahwa siswa dengan memanfaatan akun YouTube "Little Fox Chinese" dapat menguatkan literasi digital elemen learning skills meliputi keterampilan berpikir kreatif (creative thinking skill), keterampilan komunikasi (communication skill), dan keterampilan kolaborasi (collaboration skill). Meskipun siswa terkait dengan critical thinking skills mengalami kesulitan dalam menjabarkan dan menyampaikan isi dari video akun YouTube "Little Fox Chinese" disebabkan oleh kurangnya kemampuan menganalisis isi video. Akun YouTube "Little Fox Chinese" dalam pembelajaran bahasa Mandarin dapat sebagai refrensi project akhir video YouTube bahasa Mandarin siswa, karena siswa menemukan hal baru di akun YouTube tersebut dengan adanya beberapa playlist, yaitu: playlist folktales, culture, songs, dan early learning dalam bahasa Mandarin. Siswa dapat memproduksi video YouTube sendiri dengan menggunakan akun YouTube "Little Fox Chinese" sebagai refrensi video secara gratis dan YouTube dengan konten pembelajaran bahasa Mandarin dalam bentuk media digital audio-visual sedang menjamur dikalangan siswa kelas X. Sehingga dapat diketahui bahwa YouTube saat ini menjadi salah satu tujuan utama siswa dalam memperkuat literasi digital mereka.

\section{DAFTAR PUSTAKA}

Facione, P. A. 2011. Critical Thinking: What It Is and Why It Counts. Millbrae, CA: Measured Reasons and The California Academic Press.

Kabooha, R. \& Elyas, T. 2015. The Impact Using Youtube Videos on Learning Vocabulary in Saudi EFL Classrooms. Makalah disajikan dalam Conference: The 8th annual International Conference of Education, Research and Innovation, Spain, November.

Kasiram, Moh. 2010. Metodologi penelitian: Kualitatif-Kuantitatif. Malang: UIN-Maliki Press.

Lam, N. H. T.\& Woo, B. K. P. 2019. YouTube as a New Medium for Dementia Education Among Chinese Americans. Community Ment. Health J. DOI: 10.1007/s10597-019-00493-7.

Rahmawan, D. \& Mahameruaji, J.N. 2018. Potensi Youtube Sebagai Media Edukasi Bagi Anak Muda. J. Univ. Padjadjaran, 8(1), 81-98. Dari https://ejournal.upi.edu/index.php/edulib/article/view/11267.

Reyna, J., Haynam, J., \& Meier, P.C. 2018. A framework for digital media literacies for teaching and learning in higher education. J. Sage, 1-15. DOI: 10.1177/2042753018784952.

Sadirman, A. 2012. Media pendidikan pengertian, pengembangan, dan pemanfaatannya. Depok: PT Raja Grafindo Persada.

Schwab, Klaus, 2016, The Fourth Industrial Revolution: what it means, how to respond. https://www.weforum.org/agenda/2016/01/the-fourth-industrial-revolution-what-it-means-and-howto-respond/ . Diakses tgl 30 Oktober 2019.

Setyaningsih, R., Abdullah, A., Prihantor, E., \& Hustinawaty, H. 2019. Model Penguatan Literasi Digital Melalui Pemanfaatan E-Learning. J. Aspikom, No. 3, Vol 4 Dari http://jurnalaspikom.org/index.php/aspikom/article/view/333.

Sugiyono. 2011. Metode Penelitian Kuantitatif, Kualitatif dan R\&D. Bandung: Afabeta.

Suharsaputra, Uhar. 2012. Metode Penelitian: Kuantitatif, Kualitatif dan Tindakan. Bandung: PT. Refika Aditama.

YouTube Creator Academy. 2018. (online). ( https://creatoracademy.YouTube.com/page /lesson/educhannelstart?hl=id\#strategies-zippy-link-3). Diakses tgl 10 Maret 2020.

Catatan:

Artikel pernah dipresentasikan pada Seminar Nasional APSMI 24 Oktober 2020 